\title{
Small-Angle Light Scattering Studies of Three Block Copolymers
}

\author{
Irena DANIEwSKA and Claude PICOT \\ CNRS, Centre de Recherches sur les Macromolecules, \\ 67 Strasbourg, France.
}

(Received June 6, 1977)

\begin{abstract}
The superstructures of unoriented, uniaxial, and polyaxial deformed and swollen samples of SBS and SIS block copolymers have been investigated by the small-angle light scattering. It was found that the light-scattering units are rod-like and consist of polystyrene cylinders arranged in parallel. The arrangement of polystyrene cylinders with regard to the rod's axes can change and strongly depends on the preparation and treatment conditions of the samples. The mechanism of the sample deformation was explained on the basis of the rod's internal structure.
\end{abstract}

KEY WORDS Three-Block Copolymers / Polarized Light Scattering / Morphology / Deformation /

In recent years there has been considerable interest in the three-block copolymers of the styrenebutadiene-styrene (SBS) and styrene-isoprenestyrene (SIS) type, which are thermoplastic elastomers. ${ }^{1,2}$ The physical properties of these copolymers depend on their morphology, which is a consequence of the contents of the components and of thermal or mechanical treatments during the specimen preparation.

Electron microscopic and low-angle X-ray scattering studies have shown that the SBS ans SIS copolymers exhibit organized structures. ${ }^{3-7}$ This is due to the incompatibility of the components and leads to the formation of a two-phase system. Depending on the contents of the components, these structures appear as spheres, cylinders, or lamellae. $^{8-11}$

The cylinders and the lamellae are situated in parallel and form grains a few microns long. The internal structure of the grains is orderly but they are situated at random with respect to each other. ${ }^{12,13}$

Samples of SBS and SIS copolymers show optical anisotropy; they are birefringent.

The birefringence of the unstrained samples refers to the local but not microscopic birefringence

* Present address: Institute of Organic Chemsitry and Technology, Technical University of Warsaw, Warsaw, Poland. and arose mainly from the form birefringence due to the difference in average refractive index between the polybutadiene $\left(n_{\mathrm{b}}=1.52\right)$ and polystyrene $\left(n_{\mathrm{s}}=\right.$ 1.59) phase. $^{14,15}$ However an additional birefringence arising from the molecular orientation in polystyrene phase does exist, as was proved by the IR spectroscopic examinations. ${ }^{16}$

Because of the size of the grains and their birefringence these structures can scatter visible light at small angles. ${ }^{12,17,18}$

In this paper we present some results of smallangle light-scattering studies of SBS and SIS samples. The changes in the organization of the scattering units during various thermal and mechanical treatments were investigated.

\section{EXPERIMENTAL PROCEDURES}

\section{Material}

Copolymers SBS (Kraton 101) and SIS which were used in the investigation were prepared by anionic copolymerization and contained $30 \%$ of polystyrene. The superstructures characteristic of copolymers having this polystyrene content are cylinders. The samples used in the investigation were prepared by casting on a mercury surface from a $10-\%$ solution in benzene in the case of SBS copolymer and from toluene in the case of SIS copolymer. After drying at room temperature the foils were dried under reduced pressure. The 
rate of solvent evaporation was very low. It was not determined, however, that in all cases the evaporation conditions were the same. The thicknesses of different film specimens were in the range of $0.1-0.2 \mathrm{~mm}$.

\section{Method}

All light-scattering research was carried out with the photographic technique using the $\mathrm{He}-\mathrm{Ne}$ laser as a light source. The time of exposure and the distance between the sample and the film were chosen according to the properties of the preparation.

\section{RESULTS AND DISCUSSION}

\section{Unoriented Samples}

The light scattering by both SBS and SIS samples gave the four-reflex symmetrical $H_{\nabla}$ pictures of the $\pm 45^{\circ}$ type (Figure 1). The distribution of light intensity along the $\theta$ angle for the azimuthal angle $\mu=45^{\circ}$ is shown in Figure 2. According to the theory elaborated by $\mathrm{Stein}^{19-21}$ and Kawai ${ }^{22-25}$ such scattering patterns are characteristic of rodlike structures and plates having $l / e>1$ ( $l$ is the length of the plate and $e$ is its width) and optical axes at angles $0 \leqq \omega<30^{\circ} 33^{\prime}$ and $70^{\circ} 07^{\prime}<\omega \leqq 90^{\circ}$ to the axis of the rod or the plate. This model was also proposed for the investigated copolymers. The elongated grains which can be seen under an electron microscope can be regarded as model rods or plates with optical axes parallel to the polystyrene cylinders.

Theoretically the diffraction pattern $V_{\mathrm{v}}$ of this model should also consist of 4 reflexes, but in the

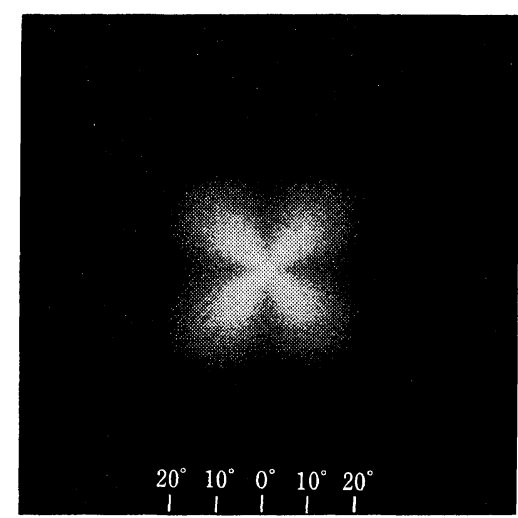

Figure 1. A typical $H_{\mathrm{v}}$-scattering pattern of samples of SBS and SIS copolymers.

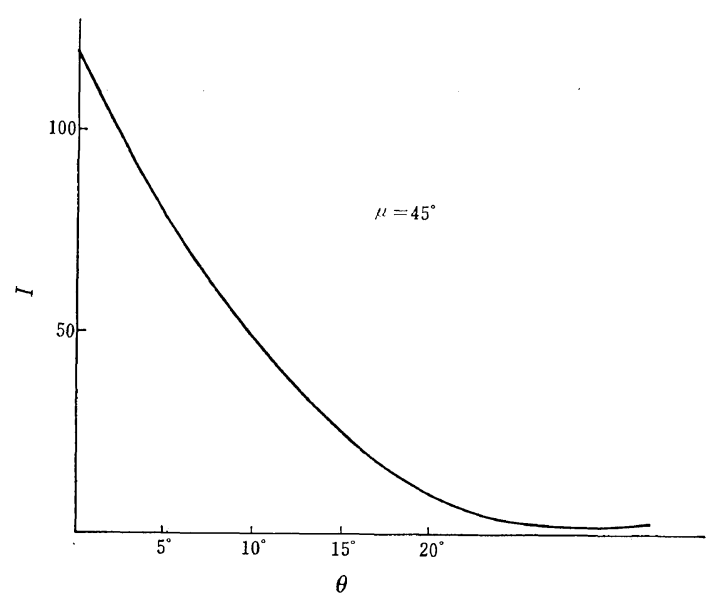

Figure 2. Distribution of intensity of $H_{\mathrm{v}}$-scattered light as a function of angle $\theta$ for azimuthal angle $\mu=$ $45^{\circ}$ ( $I$ in arbitrary units).

$0-90^{\circ}$ system. In the case of the investigated copolymers the $V_{\mathrm{v}}$ picture had the circular symmetry (Figure 3). This is probably due to the fact that the intensity and intensity distribution $I_{V_{v}}$ depend on both the anisotropic and the isotropic terms. As a result of the large difference between the refractive indexes of polystyrene and polybutadiene the isotropic term is predominant and the $V_{\mathrm{v}}$ picture has the circular symmetry. ${ }^{17,25,30}$

\section{Swollen Samples}

The SBS and SIS copolymers were swollen in isooctane, which is a selective solvent for the rubbery phase. The SBS copolymer foils preserved their shape even after several months of swelling, but their dimensions changed. Such samples were used for these studies. Although the degree of swelling was not determined quantitatively, it can be assumed that after several months the swelling was in the equilibrium state.

Light-scattering investigations of the swollen samples showed that the pictures remained qualitatively unchanged from those taken before the swelling.

A very interesting diffraction pattern is obtained after the evaporation of isooctane from a swollen sample of SBS copolymer. The picture changes from the $\pm 45^{\circ}$ type into the $0-90^{\circ}$ type (Figure 4). According to the theory developed by Stein ${ }^{19-21}$ and $\mathrm{Kawai}^{22-25}$ the pictures of this type correspond to the structures of rods with optical axes at the 


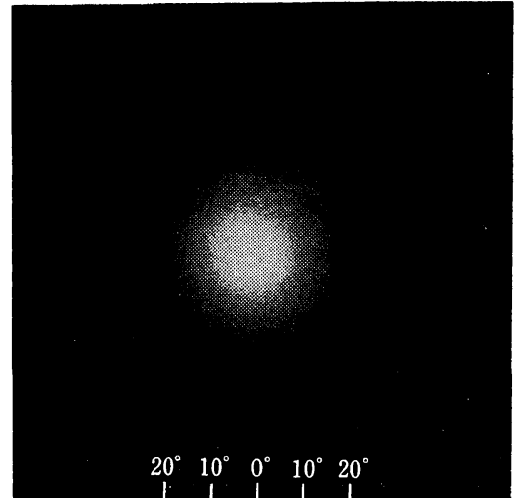

Figure 3. A typical $V_{\nabla}$ scattering pattern of samples of SBS and SIS copolymers.

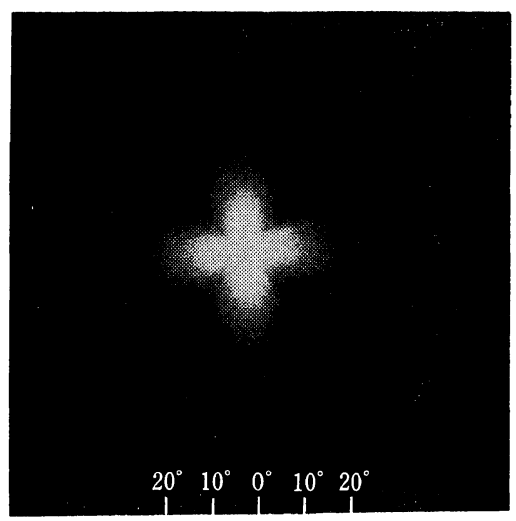

a

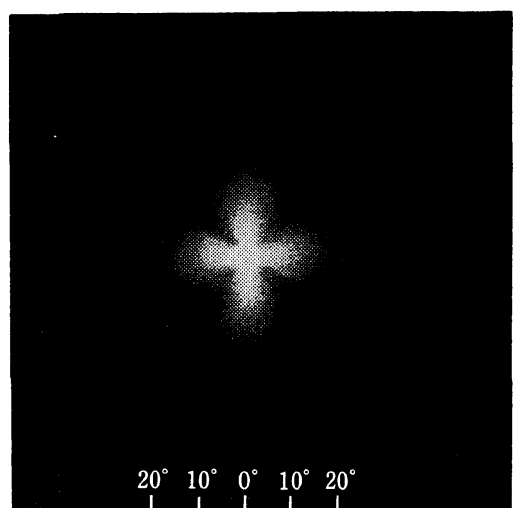

Figure 4. $H_{\nabla}$-scattering pattern of a sample of SBS copolymer after evaporation of isooctane.

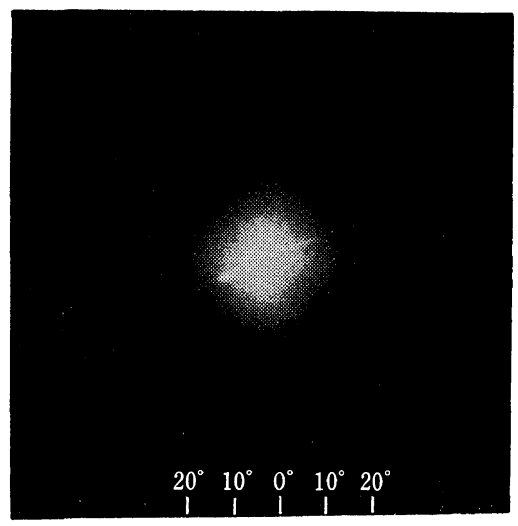

b

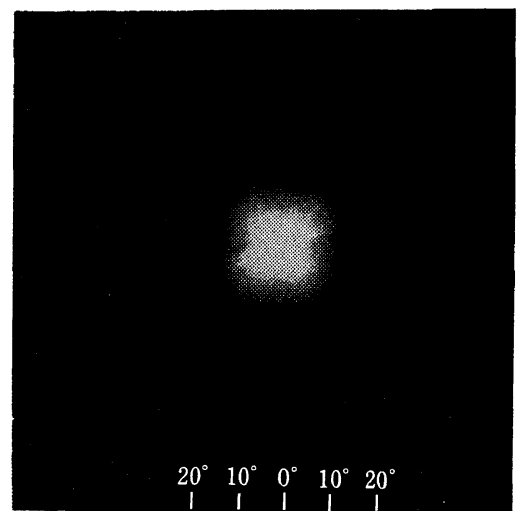

c

Figure $5 H_{\mathrm{v}}$-scattering patterns of a sample of SBS copolymer after evaporation of isooctane and heating at $65^{\circ} \mathrm{C}$ : a, the initial sample; b, $35 \mathrm{~min} ; \mathrm{c}, 55 \mathrm{~min}$.

angle $30^{\circ} 33^{\prime}<\omega<70^{\circ} 07^{\prime}$ to the axis of the rod. It appears that during the evaporation of isooctane the conformation of the polybutadiene chain changes and as a result the polystyrene cylinders become twisted in such a way that their optical axes form an angle $30^{\circ} 03^{\prime}<\omega<70^{\circ} 07^{\prime}$ with the axis of the grain. This system should be unstable as a result of strains due to rapid conformational 
changes. For this reason the relaxation of strains, for example by heating, should lead to the original picture. In order to check the correctness of this reasoning the samples were heated at $65^{\circ} \mathrm{C}$ for $55 \mathrm{~min}$ after the evaporation of isooctane. The changes observed during the heating are shown on photographs $5 \mathrm{a}-\mathrm{c}$. The originally distinct 0 $90^{\circ}$ picture (Figure 5a) after $35 \mathrm{~min}$ becomes diffuse (Figure $5 \mathrm{~b}$ ) and after $55 \mathrm{~min}$ it becomes a distinct $\pm 45^{\circ}$ picture (Figure $5 \mathrm{c}$ ). The diffusion of the picture is due to the intermediate situation of the optical axes of the polystyrene cylinders with respect to the axis of the grain when the angle $\omega=30^{\circ} 33^{\prime}$ or $70^{\circ} 07^{\prime}$.

The change from a $0-90^{\circ}$ picture to a $\pm 45^{\circ}$ picture was observed by Wilkes and $\mathrm{Vu}$ in the case of poly ( $\gamma$-1-glutamic acid) swollen in dioxane and then dried, but the authors did not explain this phenomenon. ${ }^{27}$

The SIS copolymer behaves slightly differently under the influence of isooctane. Although qualitatively the $H_{\checkmark}$ pattern remains unchanged, the copolymer finally dissolves in isooctane. Swollen foils still retaining the cohesion do not show any change of the $H_{\mathrm{v}}$ picture from $\pm 45^{\circ}$ to $0-90^{\circ}$ during the evaporation of isooctane. This may indicate that the forces acting during the polyisoprene conformation change are weaker than those acting during the polybutadiene conformation change and for this reason the orientation of the cylinders with respect to the axis of the grain remains unchanged. It is also possible that the relaxation of the strains due to conformational changes during the evaporation of the solvent is

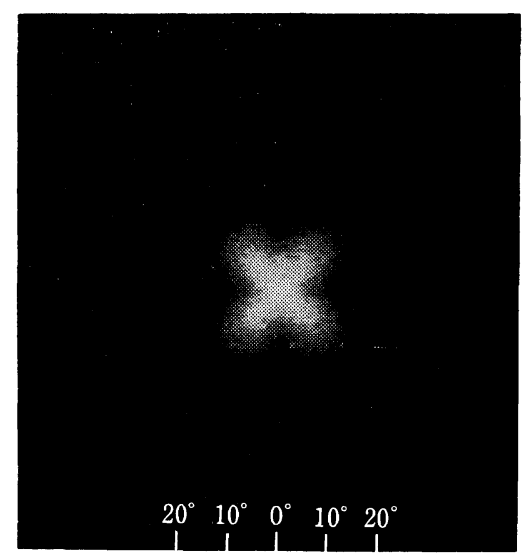

a very rapid in the case of polyisoprene and for this reason the change of the picture corresponding to the change of orientation of the polystyrene cylinders with respect to the axis of the grain is not observed.

Pedemonte and collaborators ${ }^{26}$ in their stressstrain studies on nonswollen and swollen in $n$ heptane SBS samples found that after swelling the Young's modulus and the yield stress of the samples decrease remarkably. The authors explained this observations by assuming that swelling causes the disruption of the polystyrene continuous network. The results of our investigations carried out by the small angle light scattering method indicate that the changes of the structure of swollen SBS copolymer take place mainly during the evaporation of the solvent. In this process the kind of solvent is the most important factor.

Isooctane used in our studies and $n$-heptane used by Pedemonte ${ }^{26}$ are selective solvents for polybutadiene. By evaporating they cause a pronounced change of conformation of polybutadiene chains, which leads to the change of the superstructure of the copolymer. When benzene, which is a solvent for both phases, is used in the preparation of the samples the changes of structure are not observed.

The changes in the morphological structure in swollen SBS samples were investigated by X-ray diffraction combined with electron microscopy by Folkes and collaborators. ${ }^{28}$ They found that a transformation of the cylindrical microstructure into a more complex arrangement occurs. However the manner of this transformation has not yet

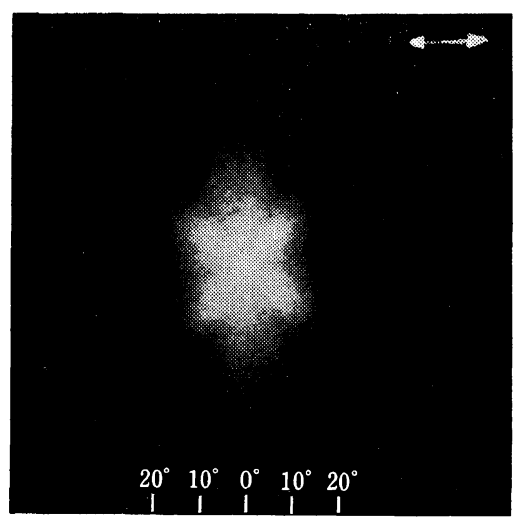

b 


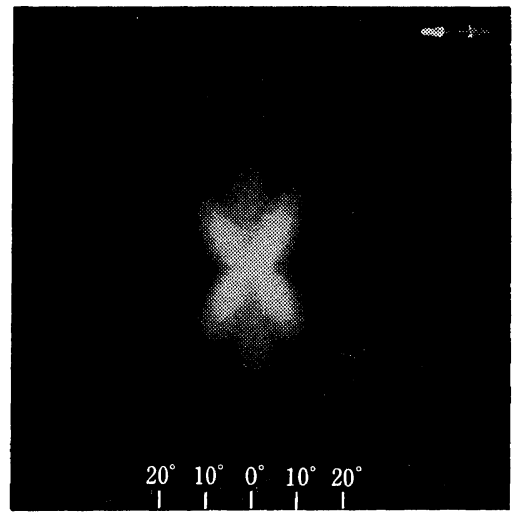

c

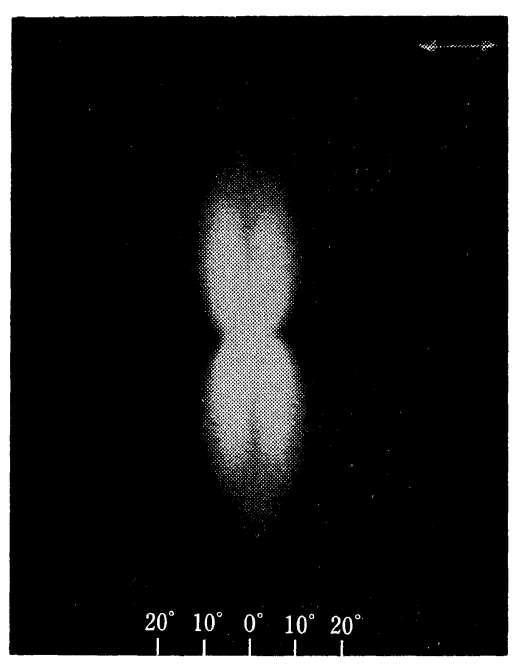

e
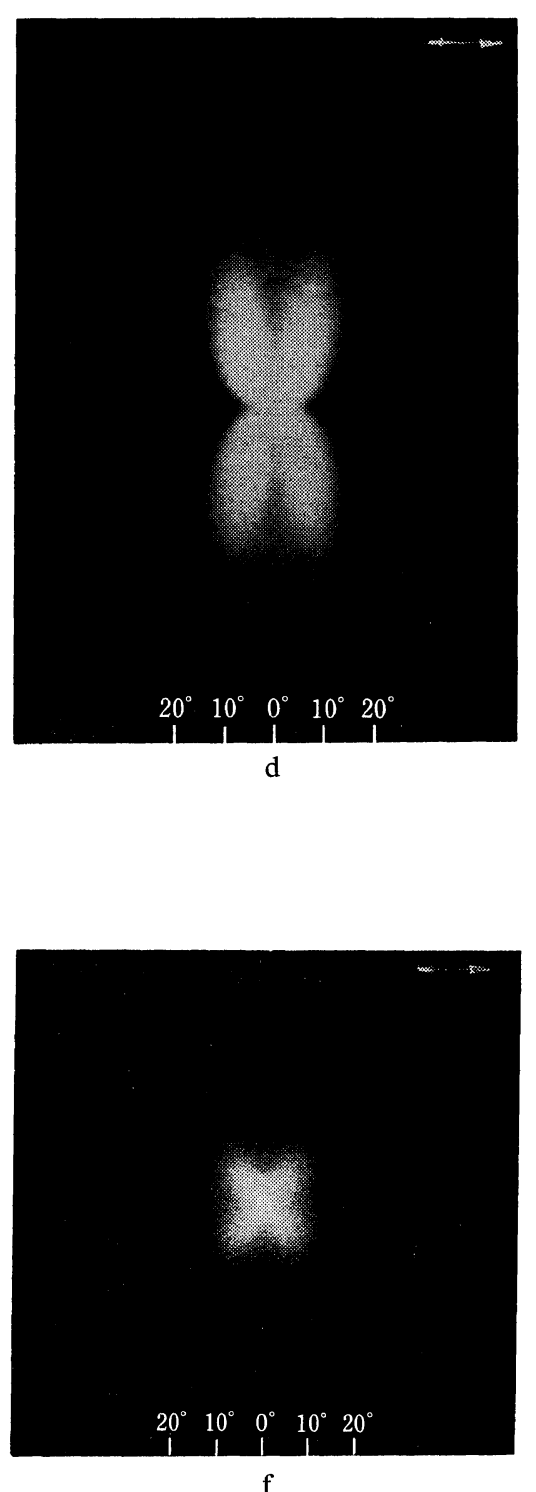

f

Figure 6. $H_{\nabla}$-scattering patterns of a stretched sample of SBS copolymer; a initial sample; $; \mathrm{b}, 50 \% ; \mathrm{c}, 100 \%$; d, $200 \%$; e, $250 \%$; f return. The arrow indicates the stretching direction.

been explained comprehensively.

\section{Uniaxial Deformation of the Samples}

The changes observed in the $H_{\nabla}$ scattering patterns of SBS and SIS samples giving the $\pm 45^{\circ}$ initial picture were analogous. They are shown in Figures 6 and 7 and are analogous to those in ref 17. The patterns change in such a way that the angular distance between the reflections decreases and at the same time the reflections are shifted in the direction perpendicular to the direction of the action of the force. This indicates deformation of the grains, which become more elongated in the direction of the action of the force. The optical axes of the grains, parallel to the polystyrene cylinders, become parallel to the direction of the deformation. The conclusions regarding the deformation of the grains drawn from the scattering patterns are in agreement with the microscopic 


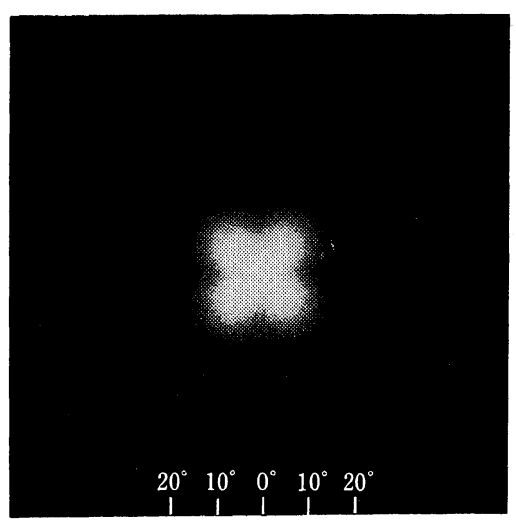

a

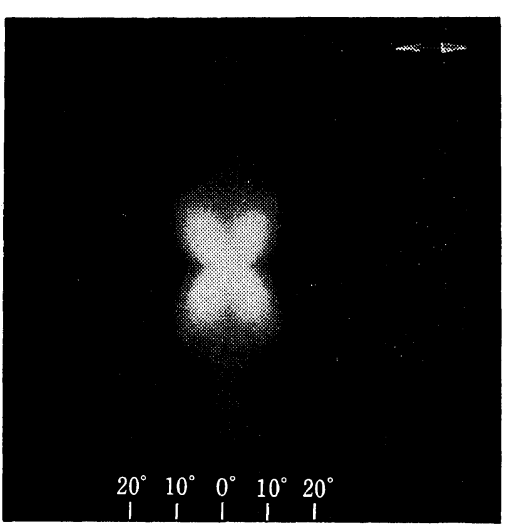

c

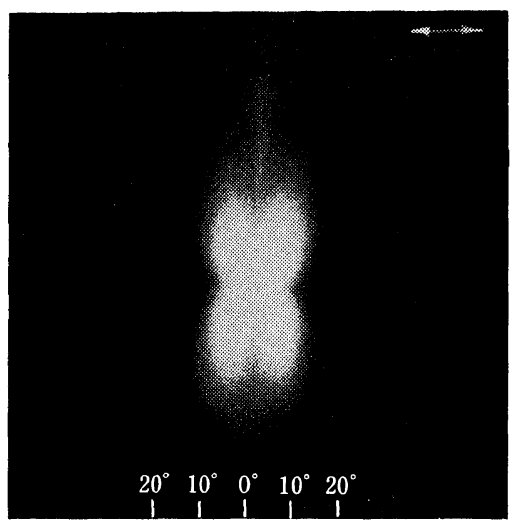

e
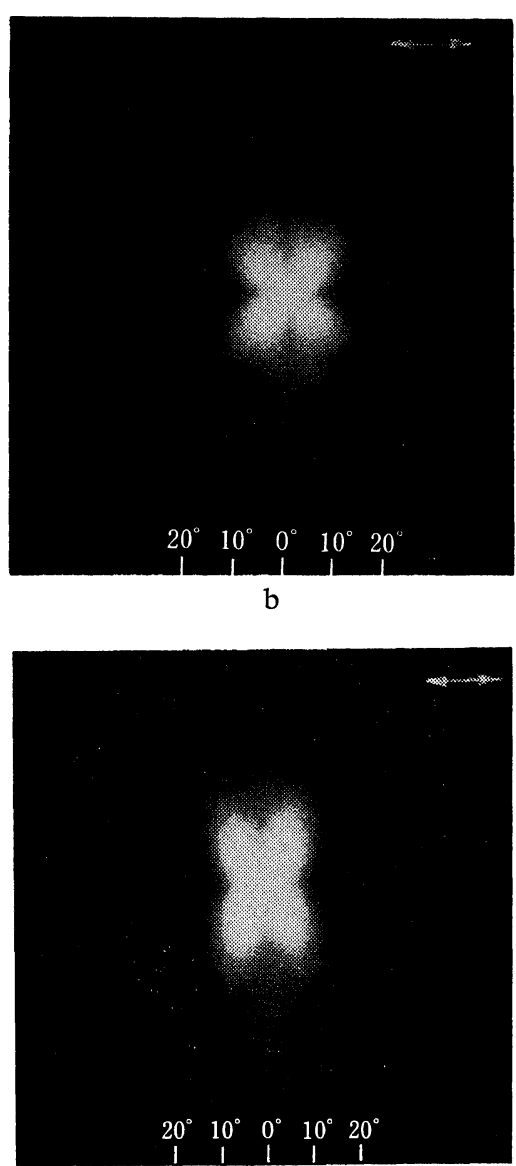

d

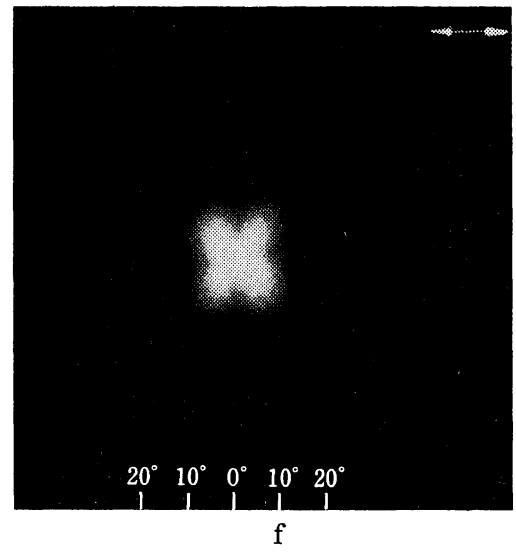

Figure 7. $H_{\mathrm{v}}$-scattering patterns of a stretched sample of SIS copolymer: a, initial sample; b, $50 \% ; \mathrm{c}, 100 \%$, d, $150 \%$; e, $200 \%$; , return. The arrow indicates the stretching direction. 
Light Scattering by Three-Block Copolymers

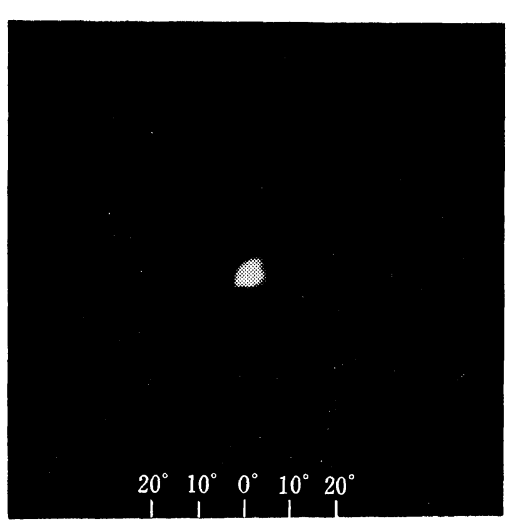

a

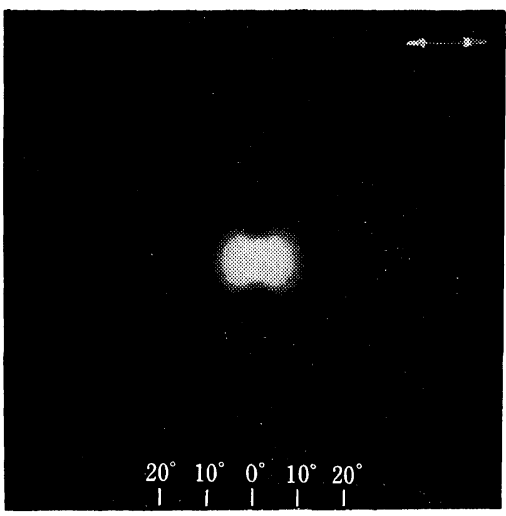

c

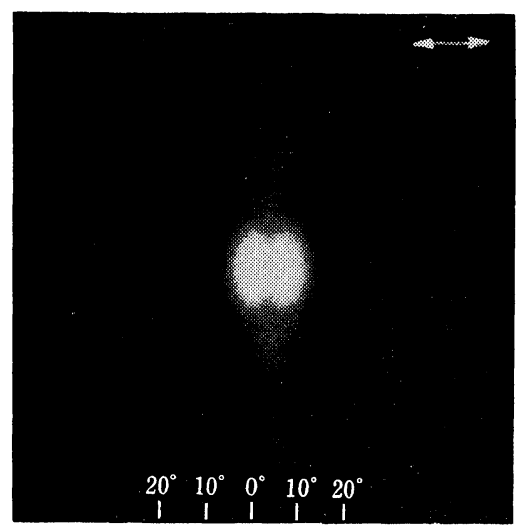

e

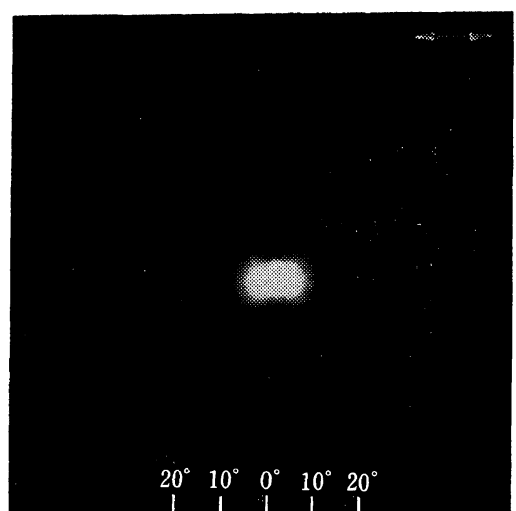

b

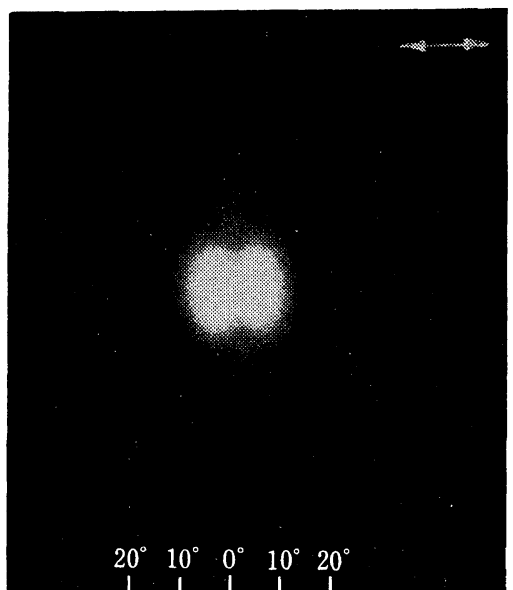

d

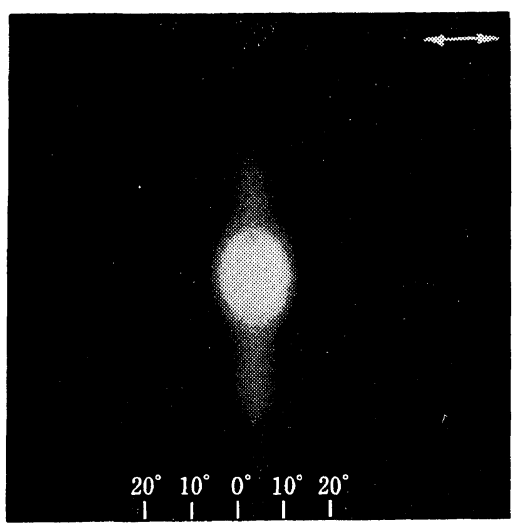

f

Figure 8. $V_{\mathrm{v}}$-scattering patterns of a stretched sample of SIS copolymer: a, initial sample; b, 20\%; c, 50\%; $100 \%$; e, $200 \% ; \mathrm{f}, 250 \%$. The arrow indicates the stretching direction. 
observations reported by Beecher and collaborators. $^{29}$

The picture of the deformation of polystyrene grains overlaps with reflections which could be

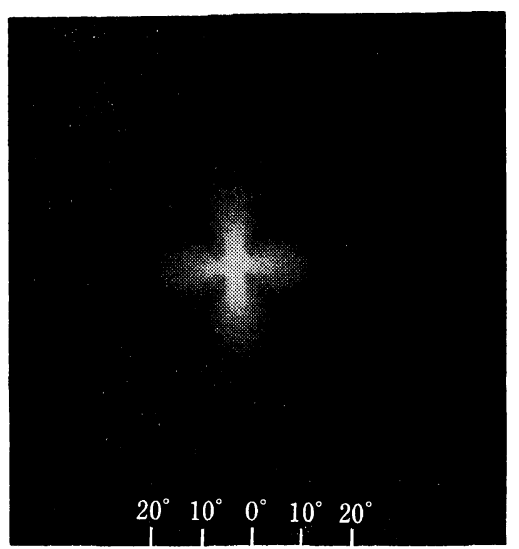

a

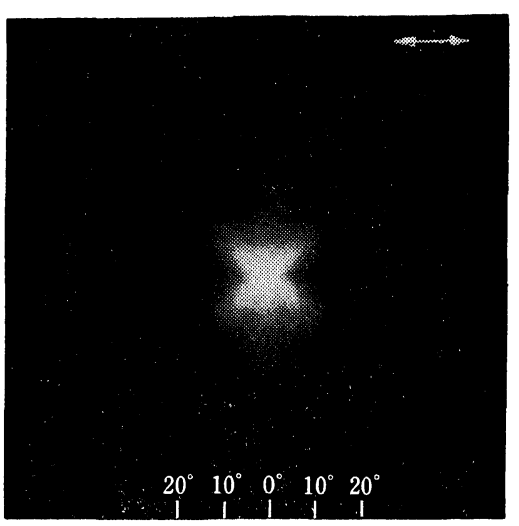

c

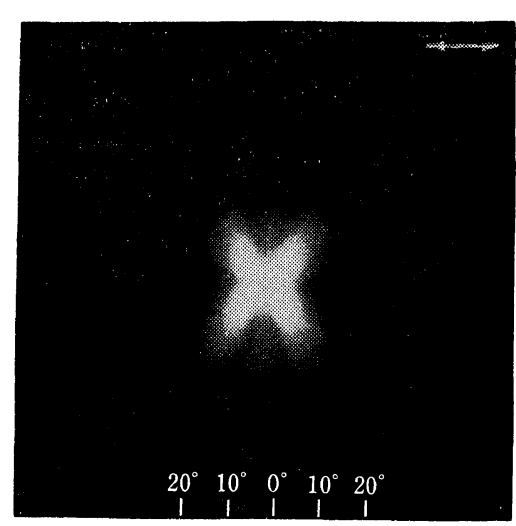

e ascribed to the deformation of rubber. This deformation precedes the deformation of polystyrene. In the photographs of the sample deformed in $50 \%$ the initial $\pm 45^{\circ}$ picture is still unchanged, whereas
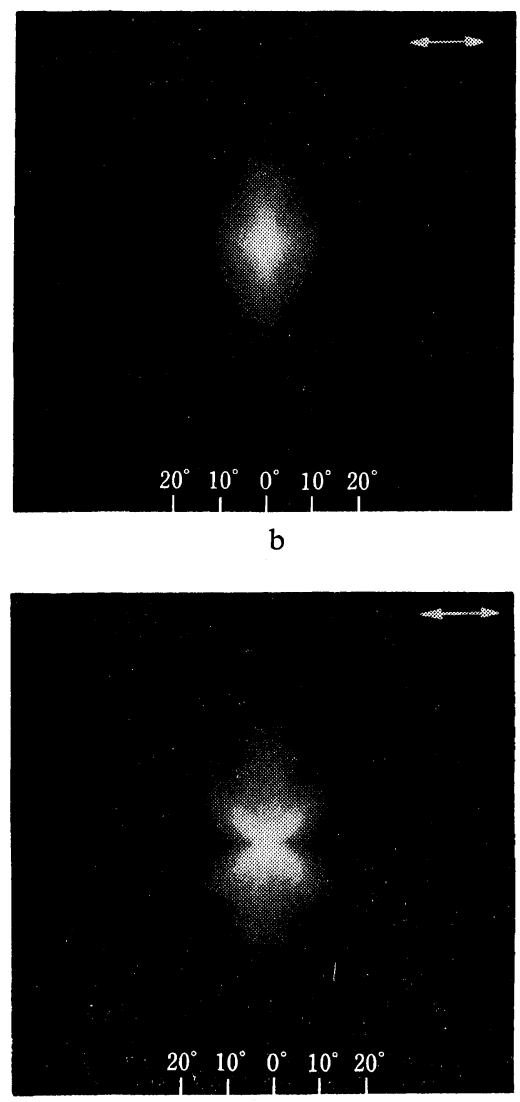

d

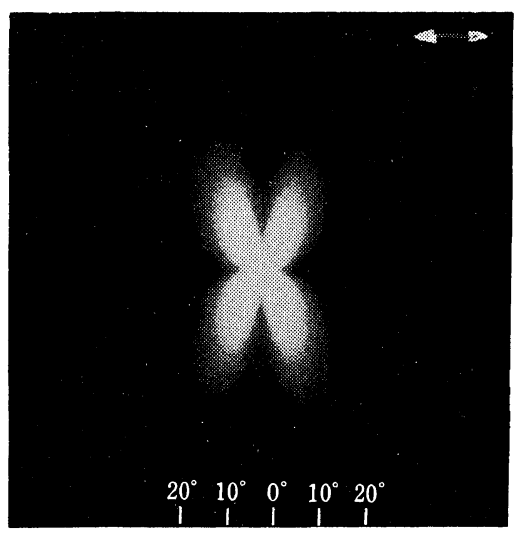

f 


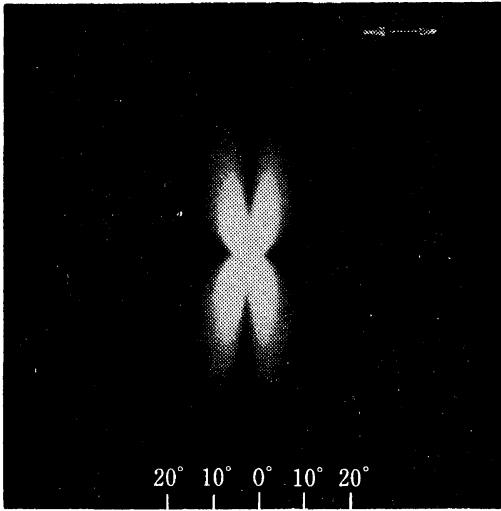

g

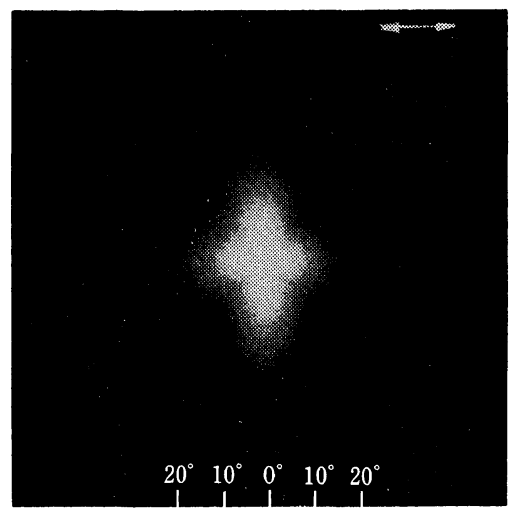

g

Figure 9. $H_{\mathrm{v}}$-scattering patterns of a sample of SBS copolymer obtained by evaporation of isooctane and stretched: a, initial sample; b, $10 \%$; c, 30\%; d, 50\%; e, 100\%,f, $150 \% ; \mathrm{g}, 200 \%$; h, return. The arrow indicates the stretching direction.

the reflection from the oriented rubber is already present. This is due to the fact that at room temperature polybutadiene is much more readily deformed than polystyrene.

The deformation of the grains at $250-\%$ stretching of the sample is very large, but it is almost completely reversible after the removal of the stretching force (Figures $6 \mathrm{f}$ and $7 \mathrm{f}$ ).

The change of $V_{v}$ patterns due to the deformation of the samples is shown in Figure 8. It can be assumed that these pictures show also the overlap of two phenomena: the deformation of rubber, which already gives the scattering pattern even at a slight $(20 \%)$ elongation (Figure $8 \mathrm{a})$, and the deformation of polystyrene grains, which gives the scattering pattern at a larger (about $100 \%$ ) elongation; in the latter case the intensity of the picture rapidly increases with increasing degree of elongation. The $V_{\mathrm{v}}$ patterns were also observed by Kawai and collaborators in their studies on the deformation of SIS copolymer containing $23 \%$ of polystyrene. The characteristic superstructures of this composition were spheres $200-700 \AA$ in diameter observed by an electron microscope. ${ }^{30}$ They do not cause the $H_{v}$ type scattering because of their small size. Probably for this reason Kawai observed only the $V_{v}$ patterns and interpreted them as the scattering caused by deformed polybutadiene. These pictures are analogous to those obtained in the present work, but they do not contain the reflection ascribed to the deformation of the polystyrene part.
The deformation of samples which give the $H_{\mathrm{v}}$ pattern of the $0-90^{\circ}$ type takes place in a somewhat different way (Figure 9). During the first stage, in which the deformation is not large (up to $50 \%$ ), the $0-90^{\circ}$ pattern changes to the $\pm 45^{\circ}$ type (through the diffuse picture) and then the deformation takes place as in the case of the system having the initial structure $\pm 45^{\circ}$ which was described earlier. This course of the deformation can be explained by assuming that at first the polystyrene cylinders change their orientation with respect to the axis of the grain passing through the limiting angle $30^{\circ} 33^{\prime}$ to the parallel arrangement. After the rearrangement inside the grain their deformation takes place as in the case described above. The scattering patterns contain also reflections which could be ascribed to the deformation of polybutadiene, but they are weaker and disappear at $150-\%$ deformation of the sample. In the present stage of the studies this phenomenon cannot be explained.

After the removal of the stretching force the diffraction pattern returns to the $0-90^{\circ}$ type (Figure 9h). This means that the system returns to its initial state.

\section{Polyaxial Deformation of the Samples}

The polyaxial deformation was caused by the pressure of ethanol on a sample in the shape of a circle which was clamped at its edges. In the first approximation the shape of the deformed sample could be regarded as a section of a sphere. ${ }^{31}$ The 


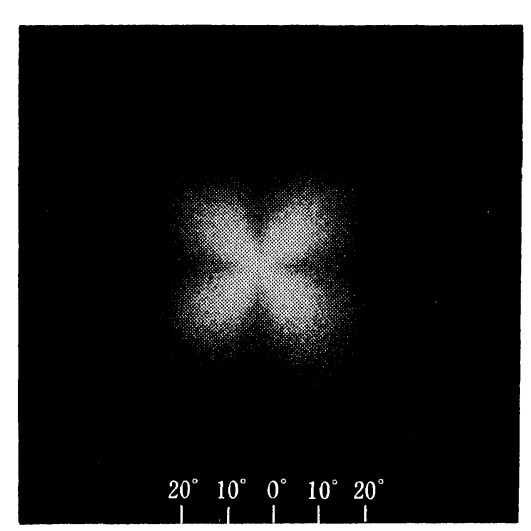

a

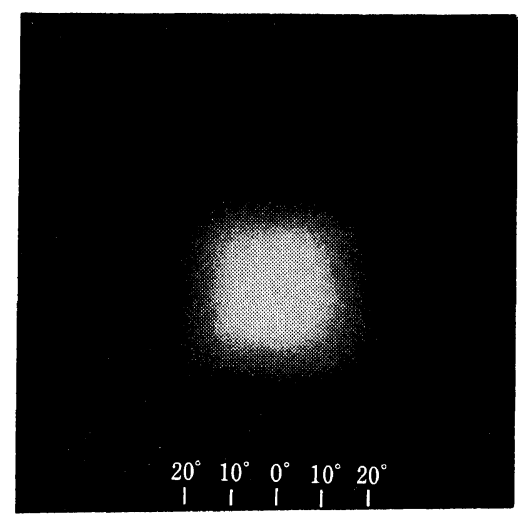

c

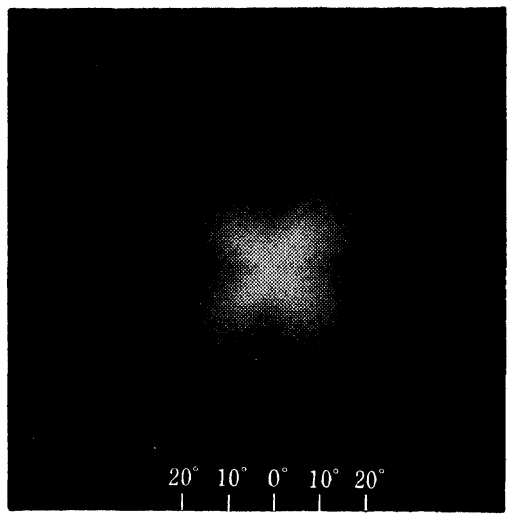

b

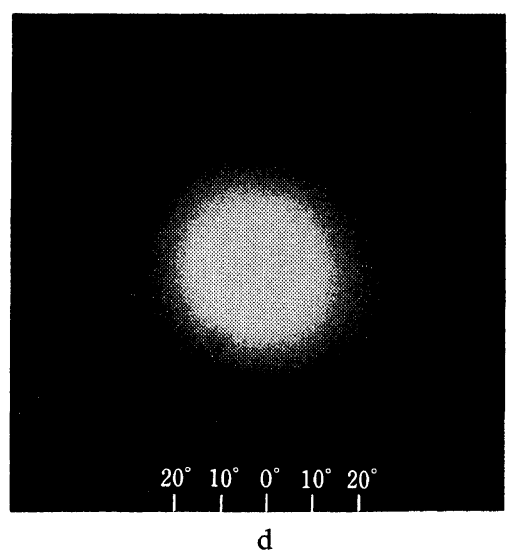

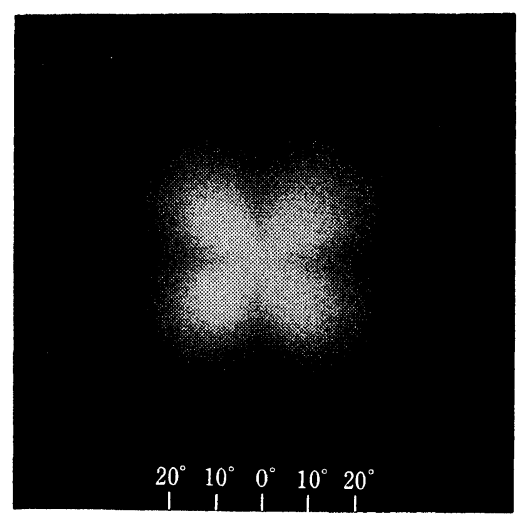

e

Figure 10. $H_{\nabla}$-scattering patterns of a polyaxially deformed sample of SIS copolymer: a, initial sample; $b, \lambda=$ $1.34^{\circ} ; \mathrm{c}, \lambda=1.56^{\circ} ; \mathrm{d}, \lambda=1.67^{\circ}$; e, return. 
degree of deformation was defined as

$$
\lambda=\left(\frac{S}{S_{0}}\right)^{1 / 2}
$$

where $S$ is the deformed surface and $S_{0}$ is the initial surface. The surface areas of deformed samples were determined by measuring the heights of the spherical cups. The change of the $H_{v}$ patterns of such deformed samples is shown in the corresponding photographs (Figure 10). The $H_{v}$ pattern of the $\pm 45^{\circ}$ type becomes diffuse and finally becomes a "halo." When the deforming forces are removed the picture returns to its initial state (Figure 10e). These observations may show that the light-scattering structures are anisotropic in shape. During the polyaxial deformation the scattering units change their position with regard to the surface of the film, while this surface is still perpendicular to the light beam. If the shape of the scattering units is spherically isotropic then the polyaxial deformation should not cause any changes in the scattering positions, so the scattering patterns should remain unchanged, especially at the first stage of deformation. If the shape is anisotropic, then such deformations will lead to a certain orientation and this ought to change the scattering pattern, as it was observed in these experiments.

\section{CONCLUSIONS}

The structure and changes in the internal organization of the heterogeneities in SBS and SIS copolymers were investigated by means of small angle light scattering. The diffraction patterns showed that the light-scattering units were grains of rodlike structure with optical axes (cylinders of polystyrene) arranged in parallel or at an angle to the rod axes. The rods are situated at random to each other. The internal structure of the rods depends on the solvent acting on the polymer. This structure influences the deformation mechanism of copolymers. In the case of polystyrene cylinders arranged parallel to the rod's axes the deformation of the system is mainly due to the deformation of the rubbery phase and leads to the parallel arranged rods. This deformation is reversible in the studied range of deformations. If the polystyrene cylinders are at an angle to the rod's axes then, at the first stage of deformation, the rearrangement of cylinders to the parallel position occurs and then the system deformation is the same as in the previous case. After removal of the stretching force the system returns to the initial state. The change of the structure of the rods in the unstressed state from an angled to the parallel position of the polystyrene cylinders was carried out by the heating of samples. This can be explained as a relaxation of strains which are in the system due to the conformational changes of the rubbery phase during the sample preparation.

\section{REFERENCES}

1. G. Holden, E. T. Bishop, and N. R. Legge, J. Polym. Sci., Part C., 26, 37 (1969).

2. L. J. Fetters, ibid., Part C, 26, 1 (1969).

3. T. Inoue, T. Soen, H. Kawai, M. Fukatsu, M. Kurata, ibid., Part B, 6, 75 (1968).

4. E. B. Bradford and E. Vanzo, ibid., Part A-1, 6, 1661 (1968)

5. von H. Hendus, K.-H. Illers, and E. Ropte, Kolloid-Z. Z. Polym., 216/217, 110 (1967).

6. M. Matsuo, Japan Plastics, 2, 6 (1968).

7. R. Mayer, Polymer, 15, 137 (1974).

8. C. Sandron, Chim. Ind. Genie Chim., 96 (1), 507 (1966).

9. C. Price, T. P. Lally, A. G. Watson, D. Woods, and M. T. Chow, Br. Polym. J., 4, 413 (1972).

10. M. Matsuo, S. Sagae, and H. Asai, Polymer, 10, 79 (1969).

11. A. Douy and B. Gallot, Makromol. Chem., 165, 297 (1973).

12. R. S. Stein, J. Polym. Sci., Polym. Lett. Ed., 9, 747 (1971).

13. E. Pedemonte, A. Turturro, U. Bianchi, and P. Devetta, Polymer, 14, 145 (1973).

14. C. Chang, D. Peiffer, and R. S. Stein, J. Polym. Sci., Part A-2, 12, 1441 (1974).

15. M. J. Folkes and A. Keller, Polymer, 12, 222 (1971).

16. M. J. Folkes and A. Keller, J. Polym. Sci., Polym. Phys. Ed., 14, 833 (1976).

17. R. S. Stein and G. L. Wilkes, ibid., Part A-2, 7, 1965 (1969).

18. G. L. Wilkes, ibid., Part A-2, 10, 767 (1972).

19. R. S. Stein, P. Erhardt, J. J. van Aartsen, S. Clough, and H. Rhodes, ibid., Part C, 13, 1 (1966).

20. R. S. Stein and R. Proud'home, ibid., Part B, 9, 595 (1971).

21. M. B. Rhodes and R. S. Stein, ibid., Part A-2, 7, 1539 (1969).

22. Y. Murakami, N. Hayashi, T. Hashimoto, and H. Kawai, Polym. J., 4, 452 (1973).

23. N. Hayashi, Y. Murakami, M. Moritani, T. Hashi- 


\section{Daniewska and C. Picot}

moto, and H. Kawai, ibid., 4, 560 (1973).

24. T. Hashimoto, Y. Murakami, N. Hayashi, and H. Kawai, ibid. 6, 132 (1974).

25. M. Matsuo, S. Nomura, T. Hashimoto, and $\mathbf{H}$. Kawai, ibid., 6, 151 (1974).

26. E. Pedemonte, A. Turturro, and G. Dondero, Br. Polym. J., 6, 277 (1974).

27. G. L. Wilkes and B. T. Vu, "Polymer Science and Technology," Vol. 1, Plenum Press, New York,
N.Y., 1973, pp 39-65.

28. M. J. Folkes, A. Keller, and J. A. Odell, J. Polym. Sci., Polym. Phys. Ed., 14, 847 (1976).

29. J. F. Beecher, L. Marker, R. D. Bradford, and S. L. Aggarwal, Rubber Chem. Technol., 40, 117 (1967).

30. T. Inoue, M. Moritani, T. Hashimoto, and $\mathbf{H}$. Kawai, Macromolecules, 4, 500 (1971).

31. J. C. Paisant, Ind. Minerale, 111 (1973). 